\title{
IMPACT OF HLA-DPB1 MATCHING ON CLINICAL OUTCOMES AFTER HAPLOIDENTICAL-RELATED HEMATOPOIETIC STEM CELL TRANSPLANTATION
}

\author{
José C. Jaime-Pérez, Carlos O. Cancela-Murrieta, lorena Salazar-Cavazos, Patrizia E. Aguilar- \\ Calderón, Rosario Salazar-Riojas, Nereida Méndez-Ramírez, Olga G. Cantú-Rodríguez, \\ CÉsar H. Gutiérrez-Aguirre, and David Gómez-Almaguer
}

Department of Hematology, Internal Medicine Division, Hospital Universitario "Dr. José E. González",

School of Medicine, Universidad Autónoma de Nuevo León, Monterrey, NL, Mexico

\begin{abstract}
Background: The impact of HLA-DPB1 compatibility and its role as a transplantation antigen in haploidentical-related hematopoietic stem cell transplant (haplo-R-HSCT) have not been established, and a negative effect on survival has been suggested. Objective: The objective of the determine was to study the frequency and clinical effects of incompatibility at the HLA-DPB1 locus in the haplo-R-HSCT setting. Methods: Clinical records and electronic files of 91 patients with a hematological disease who underwent haplo-HSCT from January 2009 to October 2017 in a university medical center were scrutinized. Overall survival (OS) was estimated by the Kaplan-Meier method; the cumulative incidence of transplant-related mortality (TRM) and relapse rates was determined. Acute graft-versus-host disease was assessed by binary logistic regression. Cox regression model with a $95 \%$ confidence interval was used to examine the association between the different variables and their effect on OS. Results: Of the 91 donor-recipient pairs, 24 (26.37\%) shared complete DPB1 identity, 60 (65.93\%) had a mismatch at one allele, and 7 (7.70\%) were mismatched at two alleles. Twenty-four different HLA-DPB1 alleles were found; the most frequent were DPB1*04:01 (34.1\%) and DPB1*04:02 (27.5\%). Two-year OS, the cumulative incidence of TRM and relapse was $51.3 \pm 6.8 \%, 28 \pm 6 \%$ and $60 \pm 7.8 \%$ for all haplo-related transplants, respectively, with no statistical difference between HLA-DPB1 matched and partially matched patients. In Cox regression analysis, no risk factors associated with OS, TRM, or relapses were identified. Conclusion: HLA-DPB1 mismatching in the haplo-R-HSCT setting did not influence transplant outcomes and was clinically tolerable. A high degree of homozygosity was found. (REV INVEST CLIN. 2020;72(2):69-79)
\end{abstract}

Key words: Haploidentical-related transplant. Human leukocyte antigen. HLA-DPB1. HSCT. Permissive mismatch. HSCT outcomes.

*Corresponding author:

José Carlos Jaime-Pérez

E-mail: carjaime7@gmail.com
Received for publication: 15-08-2019

Approved for publication: 04-10-2019

DOI: $10.24875 / R I C .19003215$

0034-8376 / (c) 2019 Revista de Investigación Clínica. Published by Permanyer. This is an open access article under the CC BY-NC-ND license (http://creativecommons.org/licenses/by-nc-nd/4.0/). 


\section{INTRODUCTION}

Allogeneic hematopoietic stem cell transplantation (allo-HSCT) is an essential therapeutic modality for many high-risk hematological diseases ${ }^{1}$. Successful outcomes after HSCT critically depend on the degree of donor-recipient matching at the human leukocyte antigen (HLA) loci; a poorly matched transplant will trigger a graft-versus-host disease (GVHD) and increase mortality ${ }^{2}$. The most frequent allogeneic transplants are those in which the donor is an HLAidentical sibling 3,4 ; however, only $30 \%$ of patients who require a transplant have a compatible family donor, and with the reduction of children per family, this percentage is decreasing ${ }^{5}$. For patients without a suitable HLA-identical donor, a family-related donor as a source of hematoprogenitors for haploidentical-related hematopoietic stem cell transplantation (haplo-RHSCT) represents a valid alternative ${ }^{1}$ with immediate donor availability in almost all patients ${ }^{6}$.

HLA-A, HLA-B, HLA-C, HLA-DRB1, and DQB1 (10/10) matching are optimum for hematopoietic stem cell transplant $(\mathrm{HSCT})^{7}$; studies suggest that analysis of the HLA-DPB1 locus can be relevant for the success of haplo-HSCT due to its numerical importance, with over 1000 alleles described to date ${ }^{8}$. The HLA-DPB locus is located near the centromere of the chromosome 6 short arm 9,10 and recombination at this point, which can give rise to a variation in offspring haplotype, frequently occurs ${ }^{10-12}$. In sibling donors matched at HLA-A, $-B$, and $-D R$, the rate of HLA-DPB1 mismatch has been estimated around 5\% due to recombination $^{13,14}$; complications as a result of this mismatching have been reported ${ }^{15}$. Thus, it is important to study the DPB1 locus in haplo-R-HSCT to confirm that the whole haplotype block is being transmitted as a unit ${ }^{12,16,17}$.

Complications in HSCT occur even in the setting of fully matched sibling transplantation ${ }^{18}$. A negative effect of incompatibility at the DPB1 locus in the unrelated HLA-identical HSCT setting has been reported ${ }^{15}$ and the previous studies have shown that the presence of DPB1 allele incompatibility resulted in significant differences in the incidence of a GVHD and disease relapse in unrelated HSCT, even if HLA 10/10 identity is present ${ }^{15}$. HLA-DP mismatches are relevant as it has been found that they participate in cellular and humoral HSC allograft rejection ${ }^{16}$.
The impact of HLA-DPB1 incompatibility in haplo-RHSCT has not been established. The objective of the present study was to assess the rate and clinical effect of incompatibility at the HLA-DPB1 locus in the haplo-R-HSCT setting in a Hispanic cohort.

\section{METHODS}

\section{Study population}

We reviewed the clinical records and electronic files of 91 consecutive self-identified Hispanic patients with mostly malignant hematological diseases who underwent haplo-R-HSCT from January 2009 to October 2017 at the Hematology Department of the Dr. José E. González University Hospital, School of Medicine of the Universidad Autónoma de Nuevo León in Monterrey, Mexico. Transplants were performed in an outpatient setting after the administration of a reduced-intensity conditioning (RIC) regimen, as previously described ${ }^{3}$. Patients provided written informed consent. The Institutional Research and Ethics Committee approved the study protocol.

\section{Haploidentical-related donor selection}

Donors were healthy first-degree relatives selected according to standard criteria and availability. HLA compatibility was assessed by intermediate resolution molecular typing methods ${ }^{19}$. Donors were classified according to HLA matching with 5/10 antigens minimal compatibility. Allele designations were assigned according to the World Health Organization Nomenclature Committee for Factors of the HLA System ${ }^{20}$.

\section{HLA-DPB1 allele determination}

All subjects were typed at intermediate resolution for HLA-DPB1 by sequence-specific probe-based hybridization. Briefly, DNA was extracted from $300 \mu \mathrm{L}$ of whole blood in ethylenediaminetetraacetic acid from donors and recipients using the automated Maxwell ${ }^{\circledR}$ 16 Blood DNA Purification System (Promega Corporation, Madison, $\mathrm{WI}$ ). In the extracted DNA, polymerase chain reaction was carried out in a PROFLEX thermocycler (Applied Biosystems ${ }^{\circledR}$, Foster City, CA) to amplify the region of the HLA-DP locus using the LABType SSO Class II DPA1 and DPB ${ }^{\circledR}{ }^{\circledR}$ Typing Test 
(One Lambda, Canoga Park, CA). DNA amplification was carried out in a PROFLEX thermocycler (Applied Biosystems ${ }^{\oplus}$, Foster City, CA) and the resulting product was transferred to a UNIPLATE ${ }^{\circledR}$ 96-well plate (Whatman GE, Healthcare Life Sciences, Madison, UK); the readings of each well and data acquisition were carried out in the LABScan ${ }^{\text {TM }} 100$ Luminex $^{\circledR} 100$ (Luminex Corporation Austin, TX). After reading, HLA Fusion $^{\text {TM }}$ software (One Lambda, Canoga Park, CA) was used to assign DPB alleles.

\section{Mobilization and CD34+ hematoprogenitors harvest}

Granulocyte colony-stimulating factor (G-CSF) at 10 $\mu \mathrm{g} / \mathrm{kg} /$ day was administered subcutaneously for 5 days. CD34+ cells were collected with a Spectra Optia (Lakewood, CO) or a COBE Spectra (Gambro, Lakewood, (C) apheresis system and $5000-7000 \mathrm{~mL}$ of blood $/ \mathrm{m}^{2}$ were processed in each apheresis to obtain $\geq 2 \times 10^{6}$ viable CD34+ cells $/ \mathrm{kg}$ of the recipient's body weight. CD34+ cells were measured by flow cytometry in a FACSCanto cytometer (Becton Dickinson, San Jose, CA).

\section{Conditioning regimen for haplo-HSCT}

A RIC scheme for adults included i.v. cyclophosphamide (Cy) $350 \mathrm{mg} / \mathrm{m}^{2} /$ day and i.v. fludarabine (Flu) $25 \mathrm{mg} / \mathrm{m}^{2} /$ day on days $-5,-4$, and -3 and i.v. melphalan $100 \mathrm{mg} / \mathrm{m}^{2} /$ day on days -2 and -1 . Infusion took place on day 0; i.v. Cy $50 \mathrm{mg} / \mathrm{kg} /$ day and Mesna $80 \%$ (Cy) on days +3 and +4 ; and oral cyclosporine A, $6 \mathrm{mg} / \mathrm{kg} /$ day and mycophenolate mofetil (MMF), $1 \mathrm{~g} /$ day on day +5 were administered for GVHD prophylaxis. In patients with a high risk of relapse, we used Cy $350 \mathrm{mg} / \mathrm{m}^{2} /$ day and Flu $25 \mathrm{mg} / \mathrm{m}^{2} /$ day on days $-7,-6$, and -5 ; busulfan (BU) $4 \mathrm{mg} / \mathrm{kg} /$ day on days $-4,-3$, and -2 ; and break on day -1 . Infusion of the graft was performed on day 0; Cy $50 \mathrm{mg} / \mathrm{kg} /$ day and Mesna $80 \%$ (Cy) on days +3 and +4 ; cyclosporine A, $6 \mathrm{mg} / \mathrm{kg} /$ day and MMF $1 \mathrm{~g} /$ day on day +5 ; and G-CSF $300 \mathrm{mcg} /$ day on days $+7-+10$. In patients with aplastic anemia, BU was not used, and each patient received conditioning according to their clinical status and transplant physician preference.

For children, conditioning consisted of a combination of $\mathrm{Cy}$ at $1500 \mathrm{mg} / \mathrm{m}^{2}$, Flu, $75 \mathrm{mg} / \mathrm{m}^{2}$, and i.v. BU, 9.6 $\mathrm{mg} / \mathrm{kg}$. As GVHD prophylaxis, patients received high-dose Cy $(50 \mathrm{mg} / \mathrm{kg})$ on days +3 and +4 . Cyclosporine A, $6 \mathrm{mg} / \mathrm{kg} / \mathrm{d}$ and MMF, $15 \mathrm{mg} / \mathrm{kg} 2$ times per day were started on day +5 . MMF was discontinued on day +35 and tapering of cyclosporine started on day +90 .

\section{Engraftment}

Neutrophil engraftment was defined as an absolute neutrophil count $\geq 500 / \mu \mathrm{L}$ for 2 consecutive days and platelet engraftment as a count $\geq 20,000 / \mu \mathrm{L}$ for 2 consecutive days, at least 7 days from the last platelet transfusion ${ }^{21}$. Engraftment was also assessed by chimerism analysis by flow cytometry; in cases with a sex mismatch, a fluorescent in situ hybridization technique to demonstrate $X$ or $Y$ chromosome was used $^{22}$. Complete donor host chimerism was defined by at least $95 \%$ donor cells and mixed chimerism by $\geq 5 \%$ recipient cells ${ }^{22,23}$. Studies were done on days 30 and 100 after haplo-R-HSCT. Primary graft failure was established by the absence of initial donor cell engraftment and if the patient never recovered from neutropenia, and secondary graft failure by loss of donor cells after initial engraftment ${ }^{24}$.

\section{Statistical analysis}

Data were analyzed using IBM SPSS Statistics for Windows v. 22.0 (IBM Corp., Armonk, NY). A descriptive analysis was performed; continuous variables were described as medians and ranges. The demographic and clinical characteristics were compared using the $\mathrm{X}^{2}$ test for categorical variables. The Kruskal-Wallis test was used for calculation of differences between variables and to compare data between groups. Overall survival (OS) was measured from the time of transplantation to time of death or last visit, with the Kaplan-Meier method and was compared using the logrank test. Cumulative incidence for relapse was measured from the time of transplantation to the time of relapse. Cumulative incidence of transplantrelated mortality (TRM) was measured from the time of transplantation to the time of death without relapse/recurrence. TRM and relapse rates were estimated using cumulative incidence curves, taking competing events into consideration and compared with the Gray test. Binary logistic regression was used to evaluate the factors associated with an increased risk of presenting acute GVHD, and the Cox proportional hazard regression model with a $95 \%$ confidence 
interval $(\mathrm{Cl})(95 \% \mathrm{Cl})$ was used to examine the association between the different variables and their effect on OS, TRM, and relapse. $p<0.05$ was considered statistically significant.

\section{RESULTS}

\section{Patients' characteristics}

Ninety-one patients with severe hematological diseases received a haploidentical (5/10 in HLA-A, HLAB, HLA-C, HLA-DRB1, and HLA-DQB1) related HSCT. Patient and donor demographics and transplantation characteristics, including donor-receptor family relationship, are shown in Table 1. Of the 91 donor-recipient pairs, 24 (26.37\%) shared complete DPB1 identity, $60(65.93 \%)$ had a mismatch at one allele, and $7(7.70 \%)$ were mismatched at two alleles, indicating a high frequency of both homozygosity and recombination at the DPB1 locus. Only 6 (25\%) of those homozygotes for DPB1 were also homozygotes for HLA-DR alleles and none shared complete identity for DQ. Among patients, the proportion of males was $60.4 \%$ and females, $39.6 \%$. The median age for all patients was 18 years (range 0-64 years); mothers (38.5\%) and fathers (20.9\%) were the more frequent donors. For the fully matched HLA-DPB1 group, median age was 16 years (range $2-52$ years) and 18.5 years for the 1-DPB1 mismatch group (range 0-64 years). The 2-DPB1 mismatch group had a median age of 19 years (range 3-48 years); there was no statistical difference in age.

The most frequent diagnoses were acute lymphoblastic leukemia (ALL) in $42(46.2 \%)$ patients, acute myeloid leukemia (AML) 16 (17.6\%), non-Hodgkin lymphoma (NHL) 6 (6.6\%), Hodgkin's lymphoma (HL) 6 $(6.6 \%)$, and aplastic anemia (AA) in $6(6.6 \%)$. The most frequent donor/recipient sex match was female to male in 31 (34.1\%) followed by male to male in 25 (27.5\%) donor-recipient pairs. More frequent CMV status was positive-positive in $51(56 \%)$ pairs and was not statistically significant (Table 1 ). Regarding $A B O$ blood type donor-recipient compatibility, 71 grafts (78\%) were matched pairs, 11 (12.1\%) minor mismatched, and 9 (9.9\%) major mismatched transplants.

There were 36 (39.6\%) deaths: 15 (41.7\%) secondary to baseline disease, including 10 with ALL, $2 \mathrm{AML}$,
$1 \mathrm{NHL}, 1 \mathrm{CML}$, and 1 aplastic anemia; 14 (38.9\%) were related to sepsis; 3 ( $8.3 \%)$ to gastrointestinal bleeding; and 4 (11.1\%) to acute kidney failure with a severe hydroelectrolytic imbalance $(n=2)$ and multiple organ dysfunction syndrome $(n=2)$.

\section{HLA-DPB1 alleles}

Twenty-four different HLA-DPB1 alleles were found in patients who received a haplo-R-HSCT; the most frequent were DPB1*04:01 (34.1\%) and DPB1*04:02 (27.5\%). Other alleles are shown in table 2.

\section{Clinical outcomes and main complications}

The median of days for myeloid and platelet engraftment was 16 and 17 for the whole cohort, with no statistical difference between the groups. Chimerism analysis was carried out, and its main results are shown in table 3. Sixty-seven (73.6\%) patients presented fever and neutropenia in the post-transplant period, whereas infections developed in 59 (64.8\%) recipients; both tended to be higher in the 1-DPB1 mismatched group. For the 2-mismatch group, no statistical differences in clinical outcomes were found.

Transfusion of blood products was required in 64 (70.3\%) patients and tended to be higher in the HLADPB1 unmatched group. Engraftment failure was documented in 18 patients (19.8\%), tending to be higher in the fully matched HLA-DPB1 allele group, with no statistical significance reached. Other salient clinical characteristics are displayed in table 3 . Acute GVHD developed in 32 (35.2\%) patients; 7 in the 0-DPB1 mismatch group, 21 in the 1-DPB1 mismatch, and 4 in the 2-DPB1 mismatch group; Grade 1 and 2 of acute GVHD developed more frequently in the unmatched group (Table 3). Binary logistic regression analysis did not show risk factors associated with this complication (Table S1).

\section{Mortality}

Thirty-six (39.6\%) patients died; 8 ( $8.80 \%$ ) belonged to the fully matched HLA-DPB1 group, and 26 (28.6\%) to the 1-mismatch group, with no statistical difference $(p=0.577)$. The remaining $2(2.20 \%)$ patients who died belonged to the 2-mismatched alleles DPB1 group. The median OS was 19 months for the 1-DPB1 
Table 1. Characteristics of 91 patients who underwent haploidentical-related hematopoietic stem cell transplant from 2009 to 2017 at "Dr. José E. González" University Hospital in Monterrey, Mexico, according to HLA-DPB1 matching

\begin{tabular}{|c|c|c|c|c|c|}
\hline Characteristic & $\begin{array}{l}\text { Haploidentical } \\
\qquad(n=91)\end{array}$ & $\begin{array}{c}0-D P B 1 \\
\text { mismatch } \\
(n=24)\end{array}$ & $\begin{array}{c}1-D P B 1 \\
\text { mismatch } \\
(n=60)\end{array}$ & $\begin{array}{c}2-D P B 1 \\
\text { mismatch } \\
(n=7)\end{array}$ & $\mathrm{p}$ \\
\hline Age, median (range) & $18(0-64)$ & $16(2-52)$ & $18.5(0-64)$ & $19(3-48)$ & 0.351 \\
\hline$<16$ years $(\%)$ & $36(39.6)$ & $12(50)$ & $21(35)$ & $3(42.9)$ & 0.439 \\
\hline$>16$ years $(\%)$ & $55(60.4)$ & $12(50)$ & $39(65)$ & $4(57.1)$ & 0.439 \\
\hline \multicolumn{6}{|l|}{ Patient gender (\%) } \\
\hline Male & $55(60.4)$ & $14(58.3)$ & $35(58.3)$ & $6(85.7)$ & 0.363 \\
\hline Female & $36(39.6)$ & $10(41.7)$ & $25(41.7)$ & $1(14.3)$ & \\
\hline \multicolumn{6}{|l|}{ Diagnosis (\%) } \\
\hline ALL & $42(46.2)$ & $13(54.2)$ & $24(40)$ & $5(71.4)$ & 0.610 \\
\hline AML & $16(17.6)$ & $4(16.7)$ & $11(18.3)$ & $1(14.3)$ & \\
\hline AA & $6(6.6)$ & $2(8.3)$ & $4(6.7)$ & $0(0)$ & \\
\hline $\mathrm{NHL}$ & $6(6.6)$ & $1(4.2)$ & $5(8.3)$ & $0(0)$ & \\
\hline $\mathrm{HL}$ & $6(6.6)$ & $0(0)$ & $6(10)$ & $0(0)$ & \\
\hline MDS & $3(3.3)$ & $2(8.3)$ & $1(1.7)$ & $0(0)$ & \\
\hline CML & $6(6.6)$ & $1(4.2)$ & $4(6.7)$ & $1(14.3)$ & \\
\hline CLL & $2(2.2)$ & $0(0)$ & $2(3.3)$ & $0(0)$ & \\
\hline SCID & $3(3.3)$ & $0(0)$ & $3(5)$ & $0(0)$ & \\
\hline Other & $1(1.1)$ & $1(4.2)$ & $0(0)$ & $0(0)$ & \\
\hline \multicolumn{6}{|c|}{ Donor/recipient sex match (\%) } \\
\hline Male to male & $25(27.5)$ & $6(25)$ & $15(25)$ & $4(57.1)$ & 0.187 \\
\hline Male to female & $13(14.3)$ & $4(16.7)$ & $8(13.3)$ & $1(14.3)$ & 0.925 \\
\hline Female to male & $31(34.1)$ & $8(33.3)$ & $21(35)$ & $2(28.6)$ & 0.940 \\
\hline Female to female & $22(24.2)$ & $6(25)$ & $16(26.7)$ & $0(0)$ & 0.295 \\
\hline \multicolumn{6}{|l|}{ Family relationship (\%) } \\
\hline Brother & $16(17.6)$ & $4(16.7)$ & $10(16.7)$ & $2(28.6)$ & 0.729 \\
\hline Sister & $16(17.6)$ & $4(16.7)$ & $11(18.3)$ & $1(14.3)$ & 0.956 \\
\hline Mother & $35(38.5)$ & $9(37.5)$ & $25(41.7)$ & $1(14.3)$ & 0.368 \\
\hline Father & $19(20.9)$ & $5(20.8)$ & $11(18.3)$ & $3(42.9)$ & 0.319 \\
\hline Son & $3(3.3)$ & $1(4.2)$ & $2(3.3)$ & $0(0.0)$ & 0.862 \\
\hline Daughter & $2(2.2)$ & $1(4.2)$ & $1(1.7)$ & $0(0.0)$ & 0.716 \\
\hline \multicolumn{6}{|l|}{ CMV status (R/D) (\%) } \\
\hline Positive/positive & $51(56)$ & $14(58.3)$ & $33(55)$ & $4(57.1)$ & 0.916 \\
\hline Positive/negative & $9(9.9)$ & $2(8.3)$ & $5(8.3)$ & $2(28.6)$ & 0.227 \\
\hline Negative/negative & $6(6.6)$ & $1(4.2)$ & $5(8.3)$ & $0(0)$ & 0.601 \\
\hline Negative/positive & $6(6.6)$ & $3(12.5)$ & $3(5)$ & $0(0)$ & 0.350 \\
\hline Unknown & $19(20.9)$ & $4(16.7)$ & $14(23.3)$ & $1(14.3)$ & 0.719 \\
\hline
\end{tabular}

ALL, acute lymphoblastic leukemia; AML, acute myeloid leukemia; AA, aplastic anemia; MDS, myelodysplastic syndrome; NHL, non-Hodgkin lymphoma; HL, Hodgkin lymphoma; CML, chronic myeloid leukemia; CLL, chronic lymphocytic leukemia; CSID, combined severe immunodeficiency; CMV, cytomegalovirus; R/D, recipient/donor. 
Table 2. Frequency of HLA-DPB1 alleles in patients who received a haploidentical transplant and their family donors

\begin{tabular}{|c|c|c|}
\hline Allele & Number & Percentage \\
\hline 04:01 & 62 & 34.1 \\
\hline 04:02 & 50 & 27.5 \\
\hline 03:01 & 14 & 7.7 \\
\hline 02:01 & 10 & 5.5 \\
\hline 05:01 & 6 & 3.3 \\
\hline 70:01:00 & 5 & 2.7 \\
\hline 01:01 & 3 & 1.6 \\
\hline 13:01 & 3 & 1.6 \\
\hline 17:01 & 3 & 1.6 \\
\hline 65:01:00 & 3 & 1.6 \\
\hline 105:01:00 & 3 & 1.6 \\
\hline 424:01:00 & 3 & 1.6 \\
\hline 14:01 & 2 & 1.1 \\
\hline $22: 01$ & 2 & 1.1 \\
\hline $57: 01: 00$ & 2 & 1.1 \\
\hline 126:01:00 & 2 & 1.1 \\
\hline 621:01:00 & 2 & 1.1 \\
\hline $02: 02$ & 1 & 0.5 \\
\hline 10:01 & 1 & 0.5 \\
\hline $11: 01$ & 1 & 0.5 \\
\hline $94: 01: 00$ & 1 & 0.5 \\
\hline 131:01:00 & 1 & 0.5 \\
\hline 155:01:00 & 1 & 0.5 \\
\hline 410:01:00 & 1 & 0.5 \\
\hline Total & 182 & 100 \\
\hline
\end{tabular}

mismatch group; for the fully matched and unmatched groups, median OS was not reached. Two-year OS was $51.3 \pm 6.8 \%$ for all haplo-related transplanted patients; $59.9 \pm 11.6 \%$ for the 0-DPB1 mismatch group, $46.4 \%$ (44.70-48.07\%) for the 1-DPB1 mismatch group, and $55.6 \pm 24.8 \%$ for the unmatched HLA-DPB1 group ( $p=0.409$ ) (Figs. $1 a$ and $b)$. In Cox regression analysis, only the dose of $\mathrm{CD} 34+$ cells was a protective factor for OS (Table S1).

The cumulative incidence of TRM at 2 years for all patients was $28 \pm 6 \%$; for the 0-DPB1 mismatch group, it was $14 \pm 8.1 \%$ versus $34 \pm 7.8 \%$ for the 1 -DPB1 mismatch group ( $p=0.099)$. The data, shown in Figs. $1 c$ and d, suggest that a significant difference might be reached by increasing the sample size. In the unmatched group, one of two deaths was due to TRM.

\section{Relapse}

Cumulative incidence of relapse at 2 years was $60 \pm$ $7.8 \%$ for all haplo-R-HSCT, $56 \pm 15.3 \%$ for the $0-D P B 1$ mismatch, and $58 \pm 10 \%$ in the 1 -DPB1 mismatch group, with no significant difference $(p=0.750)$ (Figs. $1 \mathrm{e}$ and $\mathrm{f}$ ). For the unmatched group, relapse developed in 4 of $7(57.1 \%)$ patients. No risk factors were identified in Cox regression analysis of the cumulative incidence of relapse and TRM (Table S2).

\section{DISCUSSION}

The major limitations for haplo-HSCT allografting are the high incidence of TRM, graft failure, GVHD, and poor OS rates ${ }^{25}$. Nevertheless, for patients who lack an HLA-identical sibling, the haplo-R-HSC transplant modality represents a potentially life-saving alternative. HLA-matched sibling donors share both alleles of HLA-A, -B, -C, -DR, -DQ, and -DP (12/12). Exceptions do occur in $1-5 \%$ of cases, accounted for by genomic recombination, with the highest frequency reported for HLA-DP due to at least one recombination hotspot between DP and $\mathrm{DQ}^{26-28}$. HLA polymorphisms represent a barrier to HSC transplantation because HLA incompatibilities at the allele level can be recognized by alloreactive $T$ lymphocytes ${ }^{29}$. HLA-DPB1 is the first locus explored as a model for clinically permissive donor-recipient HLA mismatches, and this has led to increased interest into HLA-DP role in unrelated HSCT. Thus, some HLA-DPB1 mismatches are considered permissive when the expressed T-cell epitope structure is similar in donor-recipient pairs, while others are considered non-permissive with greater differences in T-cell epitope structure, which may put the recipient at increased risk for suboptimal outcomes ${ }^{30}$. A negative effect of DPB1 locus incompatibility in unrelated HLA-identical HSCT has been documented ${ }^{31}$. Nevertheless, the relevance of HLA-DPB1 compatibility in the haplo-R-HSCT setting has not been established. Thus, we assessed the impact of incompatibility at this locus on clinical outcomes after related haploHSCT in a Hispanic cohort.

Importantly, HLA-DPB1 typing results in our cohort showed that 24 of 91 patients did not have allelic 
Table 3. Clinical outcomes according to HLA-DPB1 matching of 91 Hispanic patients with diverse hematologic diseases who received a haploidentical-related transplant from 2009 to 2017 in Northeast Mexico

\begin{tabular}{|c|c|c|c|c|c|}
\hline & $\begin{array}{l}\text { All patients } \\
\quad(n=91)\end{array}$ & $\begin{array}{c}0 \text { mismatched } \\
\text { DPB1 } \\
(n=24)\end{array}$ & $\begin{array}{c}1 \text { mismatched } \\
\text { DPB1 } \\
(n=60)\end{array}$ & $\begin{array}{c}2 \text { mismatched } \\
\text { DPB1 } \\
(n=7)\end{array}$ & $\mathrm{p}$ \\
\hline \multicolumn{6}{|c|}{ Engraftment days (median, range) } \\
\hline Myeloid & $16(10-56)$ & $16(10-56)$ & $16(11-43)$ & $16.5(14-24)$ & 0.678 \\
\hline Platelets & $17(9-56)$ & $17(10-56)$ & $17(9-30)$ & $18.5(12-24)$ & 0.542 \\
\hline \multicolumn{6}{|l|}{ Chimerism (\%) 30 days } \\
\hline Complete chimerism & $53(58.2)$ & $13(54.2)$ & $37(61.7)$ & $3(42.8)$ & 0.429 \\
\hline Mixed chimerism & $12(13.2)$ & $5(20.8)$ & $5(8.3)$ & $2(28.6)$ & 0.745 \\
\hline Not available & $263(28.6)$ & $6(25)$ & $18(30)$ & $2(28.6)$ & 0.216 \\
\hline \multicolumn{6}{|l|}{100 days } \\
\hline Complete chimerism & $37(40.7)$ & $8(33.3)$ & $25(41.7)$ & $4(57.1)$ & 0.378 \\
\hline Mixed chimerism & $8(8.8)$ & $4(16.7)$ & $3(5)$ & $1(14.3)$ & 0.076 \\
\hline Not available & $46(50.5)$ & $12(50)$ & $32(53.3)$ & $2(28.6)$ & 0.533 \\
\hline \multicolumn{6}{|c|}{ Complications after HSCT (\%) } \\
\hline Fever and neutropenia & $67(73.6)$ & $15(62.5)$ & $47(78.3)$ & $5(71.4)$ & 0.328 \\
\hline Infections (any type) & $59(64.8)$ & $15(62.5)$ & $40(66.7)$ & $4(57.1)$ & 0.849 \\
\hline Transfusions & $64(70.3)$ & $16(66.7)$ & $42(70)$ & $6(85.7)$ & 0.621 \\
\hline Mucositis (I-IV) & $20(22.0)$ & $6(25)$ & $12(20)$ & $2(28.6)$ & 0.802 \\
\hline CMV PCR $(+)$ & $14(15.4)$ & $5(20.8)$ & $7(11.7)$ & $2(28.6)$ & 0.347 \\
\hline Acute GVHD & $32(35.2)$ & $7(29.2)$ & $21(35)$ & $4(57.1)$ & 0.394 \\
\hline Grade I & $13(14.3)$ & $2(8.3)$ & $9(15)$ & $2(28.6)$ & 0.758 \\
\hline Grade II & $14(15.4)$ & $4(16.7)$ & $8(13.3)$ & $2(28.6)$ & 0.593 \\
\hline Grade III & $6(6.6)$ & $1(4.2)$ & $5(8.3)$ & $0(0)$ & 0.531 \\
\hline Grade IV & $1(1.1)$ & $0(0)$ & $1(1.7)$ & $0(0)$ & 0.773 \\
\hline Chronic GVHD & $21(23.1)$ & $5(20.8)$ & $14(23.3)$ & $2(28.6)$ & 0.910 \\
\hline Relapse & $33(36.3)$ & $9(37.5)$ & $20(33.3)$ & $4(57.1)$ & 0.459 \\
\hline Engraftment failure & $18(19.8)$ & $7(29.2)$ & $9(15)$ & $2(28.6)$ & 0.281 \\
\hline Death & $36(39.6)$ & $8(33.3)$ & $26(43.3)$ & $2(28.6)$ & 0.577 \\
\hline
\end{tabular}

differences in HLA-DPB1, and therefore, 60, two-thirds, were true HLA-DPB1 haplo-R-HSCT. This reflects a high degree of homozygosity among the self-identified Hispanic individuals of the study population, and frequent recombination at this locus, since seven patients encoded no common DPB1 allele. Interestingly, only a quarter of HLA-DPB1 homozygous were also homozygous for HLA-DR and none shared both DQ alleles.

The most frequent HLA-DPB1 alleles found were DPB1*04:01 (34.1\%) and DPB1*04:02 (27.5\%).
Studies in the United States report a frequency for DPB $1 * 04: 01$ allele from $10.4 \%$ to $38.90 \%$ and $12 \%$ to $62.0 \%$ for DPB1*04:0232-35. In a cohort of unrelated European American stem cell donors, this frequency was $43.8 \%$ for $\mathrm{DPB} 1^{*} 04: 01$ and $11.5 \%$ $\mathrm{DPB} 1 * 04: 02^{36}$. For Latin-American countries, DPB $1 * 04: 02$ allele frequencies range from $13.2 \%$ to $89.10 \%$, whereas for the DPB1*04:01 allele, it is $0 \%$ to $15.3 \%^{34,37-42}$, reflecting considerable expression heterogeneity of HLA molecules among populations across the continent. 
Figure 1. (A) OS for 91 haploidentical-related hematopoietic stem cell recipients receiving reduced-intensity conditioning. (B) Comparison of OS between patients fully matched and partially matched at the HLA-DPB1 allele. (C) Cumulative incidence of TRM for haploidentical-related hematopoietic stem cell transplants in 91 patients. (D) Comparison of cumulative incidence for TRM between patients fully matched and partially matched at the HLA-DPB1 allele. (E) Cumulative incidence of relapse in 91 haploidentical-related hematopoietic stem cell allografted patients following reduced-intensity conditioning. (F) Comparison of cumulative incidence for relapse between patients fully matched and partially matched at the HLA-DPB1 allele. OS, overall survival; TRM, transplant-related mortality.
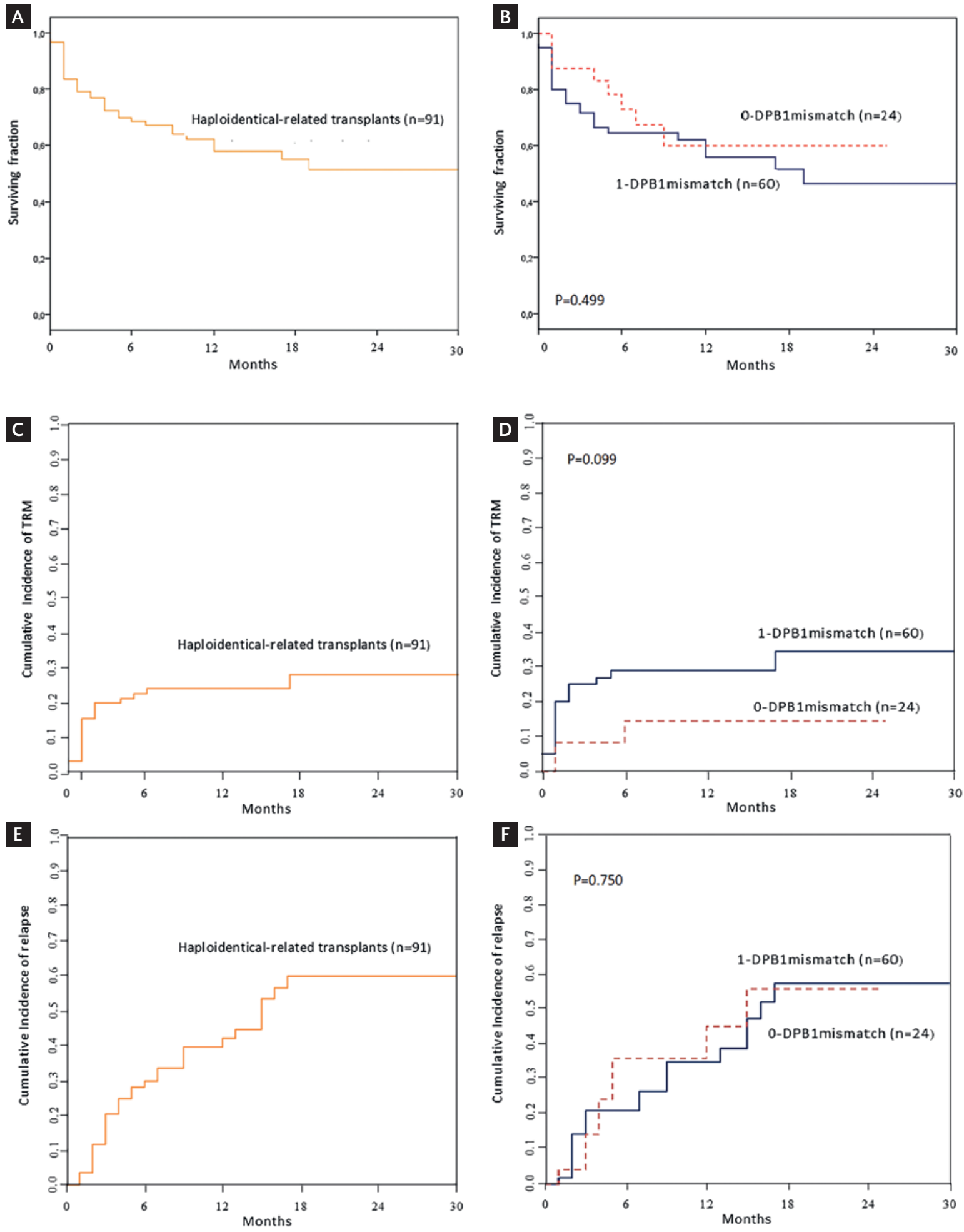
Infections are a common problem after haplo-HSCT and account for substantial morbidity and mortality ${ }^{42}$. Fever and neutropenia and the need for transfusion in the post-transplant period were the main complications in our haplo-R-HSCT cohort, similar to the studies that found a higher incidence of these complications in the haploidentical than in HLA-identical transplants ${ }^{43}$.

Acute GVHD affects $10-50 \%$ of HSCT recipients even with the use of standard prophylactic immunosuppressive regimens ${ }^{44}$. It developed in $35.2 \%$ of our recipients and tended to be higher in mismatched than in HLA-DPB1 fully matched recipients, although the difference was not statistically significant. Grade 1 and 2 acute GVHD tended to develop in the mismatched group, with no risk factor associated with an increased incidence of this complication. No significant difference according to DPB1-allele matching was found in chronic GVHD; nevertheless, this complication tended to be higher in the one-mismatch group.

Relapse is the main cause of treatment failure after allogeneic $\mathrm{HSCT}^{45}$ and the principal cause of death 100 days after HLA-identical sibling and unrelated allografting ${ }^{46}$. One study found that the hazard for relapse between patients matched at $-A,-B,-C,-D R$, and -DQ alleles and mismatched at HLA-DPB1 was lower than for patients matched at DPB1, reflecting the importance of the graft versus leukemia effect ${ }^{47}$. In contrast, in patients mismatched for at least one other HLA allele, the impact of DPB1 mismatch was not significant ${ }^{48}$. In our haplo-R-HSCT cohort, cumulative incidence of relapse at 2 years was $60 \%$, similar to the general rate previously reported $^{3}$. In another study in patients with newly diagnosed AML that received a haplo-unrelated transplant, the cumulative incidence of relapse at 3 years was $70 \%{ }^{49}$. In our group, patients matched at the HLA-DPB1 allele had a relapse rate of $56 \%$ versus $58 \%$ in the mismatched group at 2 years; in contrast, in studies on unrelated haploidentical transplants mismatched at HLA-DPB1, a significant difference in relapse rate between these groups was found ${ }^{15,50}$.

Haplo-HSCT leads to a higher incidence of TRM and overall mortality compared with HLA-identical sibling
$\mathrm{HSCT}^{43}$. OS in our study was $51.3 \%$, similar to $58 \%$ in another report ${ }^{51}$. Importantly, although no statistical difference between fully and partially compatible recipients at the HLA-DPB1 allele was documented, fully matched recipients had a considerably lower TRM. This strongly suggests that a significant difference might be reached by increasing the number of patients studied; therefore, statistically powered cooperative studies are needed to answer this question. Remarkably, the only risk factor statistically associated with an increased risk of mortality was a lower dose of CD34+ cells.

In our cohort, TRM at 1 year was $24 \%$; a recent systematic review and meta-analysis found $5 \%-42 \%$ rate after 12 months $^{52}$. For fully and partially HLA-DPB1 matched patients, no difference in TRM or any risk factor associated with higher mortality existed, which supports recent observations that HLA-DP antigens can be a model for clinically permissive mismatches eliciting limited T-cell alloreactivity ${ }^{16}$. Importantly, this is the first study to analyze the clinical relevance of compatibility at the HLA-DPB1 locus in patients who receive a haplo-R-HSCT in an ambulatory setting after RIC.

It is relevant to underscore than in pediatric populations, and more so in those from low- and middle-income countries, finding a complete match for major histocompatibility complex haplotypes is considerably more difficult. This has stimulated the development of alternative donor sources, including haploidentical grafts, despite this type of haplo-HSCT carries a higher risk for graft failure and GVHD. In this respect, post-transplant $\mathrm{Cy}$ administration has resulted in improved outcomes, helping to advance the field of pediatric haplotransplantation ${ }^{53,54}$.

Some limitations of our study should be noted, including its retrospective design and the limited number of allografted patients; prospective, larger studies in different populations are needed to confirm these findings.

In conclusion, mismatching for DPB1 did not lead to significant differences for main transplant outcomes in a cohort suffering severe hematologic disease, and mismatching at this locus was clinically tolerable. 


\section{SUPPLEMENTARY DATA}

Supplementary data are available at Revista de Investigación Clínica online (www.clinicalandtranslationalinvestigation.com). These data are provided by the corresponding author and published online for the benefit of the reader. The contents of supplementary data are the sole responsibility of the authors.

\section{REFERENCES}

1. Adhikari J, Gyawali B, Sharma P, Bhatt VR. Outcomes of haploidentical transplant compared with matched donor allogeneic stem cell transplant. Future Oncol. 2017;13:935-44.

2. Shaw BE, Potter MN, Mayor NP, Pay AL, Smith C, Goldman JM, et al. The degree of matching at HLA-DPB1 predicts for acute graft-versus-host disease and disease relapse following haematopoietic stem cell transplantation. Bone Marrow Transplant. 2003:31:1001-8

3. Jaime-Pérez JC, Salazar-Cavazos L, Aguilar-Calderón P, HerreraGarza JL, Gutiérrez-Aguirre CH, Gómez-Almaguer D, et al. Assessing the efficacy of an ambulatory peripheral blood hematopoietic stem cell transplant program using reduced intensity conditioning in a low-middle-income country. Bone Marrow Transplant. 2019:54:828-38.

4. Ma YR, Xu LP, Zhang XH, Yan $\mathrm{CH}$, Wang $\mathrm{Y}$, Wang $F R$, et al. Comparable post-relapse outcomes between haploidentical and matched related donor allogeneic stem cell transplantation. Bone Marrow Transplant. 2017;52:409-14

5. Shiina T, Hosomichi K, Inoko H, Kulski JK. The HLA genomic loci map: expression, interaction, diversity and disease. J Hum Genet. 2009:54:15-39.

6. Reisner Y, Aversa F, Martelli MF. Haploidentical hematopoietic stem cell transplantation: state of art. Bone Marrow Transplant. 2015;50 Suppl 2:S1-5

7. Shaw S, Johnson AH, Shearer GM. Evidence for a new segregant series of $B$ cell antigens that are encoded in the HLA-D region and that stimulate secondary allogenic proliferative and cytotoxic responses. J Exp Med. 1980;152:565-80.

8. Robinson J, Halliwell JA, Hayhurst JD, Flicek P, Parham P, Marsh SG, et al. The IPD and IMGT/HLA database: allele variant databases. Nucleic Acids Res. 2015;43:D423-31.

9. Shaw BE, Mayor NP, Russell NH, Apperley JF, Clark RE, Cornish J, et al. Diverging effects of HLA-DPB1 matching status on outcome following unrelated donor transplantation depending on disease stage and the degree of matching for other HLA alleles. Leukemia. 2010;24:58-65

10. Gaschet J, Gallot G, Ibisch C, Lim A, Even J, Vivien R, et al. Acute graft-versus-host disease after bone marrow transplantation with a single HLA-DPB1*1001 mismatch: involvement of different TCRBV subsets. Bone Marrow Transplant. 1998;22:385-92.

11. Meyer CG, May J, Schnittger L. HLA-DP Part of the concert. Immunol Today. 1997:18:58-61.

12. Aversa F, Tabilio A, Velardi A, Cunningham I, Terenzi A, Falzetti $F$, et al. Treatment of high-risk acute leukemia with T-cell-depleted stem cells from related donors with one fully mismatched HLA haplotype. N Engl J Med. 1998;339:1186-93.

13. Büchler T, Gallardo D, Rodríguez-Luaces M, Pujal JM, Grañena A. Frequency of HLA-DPB1 disparities detected by reference strand-mediated conformation analysis in HLA-A,-B, and DRB1 matched siblings. Hum Immunol. 2002;63:139-42.

14. Nomura N, Ota M, Kato S, Inoko H, Tsuji K. Severe acute graftversus-host disease by HLA-DPB1 disparity in recombinant family of bone marrow transplantation between serologically HLAidentical siblings: an application of the polymerase chain reaction-restriction fragment length polymorphism method. Hum Immunol. 1991;32:261-8.

15. Shaw BE, Marsh SG, Mayor NP, Russell NH, Madrigal JA. HLADPB1 matching status has significant implications for recipients of unrelated donor stem cell transplants. Blood. 2006; 107:1220-6.
16. Fleischhauer $\mathrm{K}$, Shaw BE. HLA-DP in unrelated hematopoietic cell transplantation revisited: challenges and opportunities. Blood. 2017;130:1089-96

17. Kwon M, Martínez-Laperche C, Balsalobre P, Serrano D, Anguita J, Gayoso J, et al. Early peripheral blood and T-cell chimerism dynamics after umbilical cord blood transplantation supported with haploidentical cells. Bone Marrow Transplant. 2014; 49:212-8

18. Servais S, Baron F, Beguin Y. Allogeneic hematopoietic stem cell transplantation (HSCT) after reduced intensity conditioning. Transfus Apher Sci. 2011;44:205-10.

19. FACT-JACIE. International Standards for Cellular Therapy Product Collection, Processing, and Administration. $4^{\text {th }}$ ed. JACIE; 2014

20. Marsh SG, Albert ED, Bodmer WF, Bontrop RE, Dupont B, Erlich $\mathrm{HA}$, et al. Nomenclature for factors of the HLA system, 2010. Tissue Antigens. 2010;75:291-455.

21. Tiwari AK, Arora D, Dara RC, Dorwal P, Sood N, Misra R, et al. Newly established stem cell transplant program: 100 days follow-up of patients and its comparison with published indian literature. Indian J Med Paediatr Oncol. 2016;37:168-73.

22. Pinkel D, Straume T, Gray JW. Cytogenetic analysis using quantitative, high-sensitivity, fluorescence hybridization. Proc Nat Acad Sci U S A. 1986;83:2934-8.

23. Valcárcel $D$, Martino $R$, Caballero $D$, Mateos MV, Pérez-Simón JA, Canals C, et al. Chimerism analysis following allogeneic peripheral blood stem cell transplantation with reduced-intensity conditioning. Bone Marrow Transplant. 2003;31:387-92.

24. Olsson RF, Logan BR, Chaudhury S, Zhu X, Akpek G, Bolwell BJ, et al. Primary graft failure after myeloablative allogeneic hematopoietic cell transplantation for hematologic malignancies. Leukemia. 2015;29:1754-62

25. Kekre N, Antin JH. Hematopoietic stem cell transplantation donor sources in the 21st century: choosing the ideal donor when a perfect match does not exist. Blood. 2014;124:334-43.

26. Martin M, Mann D, Carrington M. Recombination rates across the HLA complex: use of microsatellites as a rapid screen for recombinant chromosomes. Hum Mol Genet. 1995:4:423-8.

27. Cullen M, Erlich H, Klitz W, Carrington M. Molecular mapping of a recombination hotspot located in the second intron of the human TAP2 locus. Am J Hum Genet. 1995;56:1350-8.

28. Gallardo $D$ Brunet $S$, Torres $A$, Alonso-Nieto $M$, Vallejo $C$, Jiménez $A$, et al. Hla-DPB1 mismatch in HLA-A-B-DRB1 identical sibling donor stem cell transplantation and acute graft-versushost disease. Transplantation. 2004;77:1107-10.

29. Tiercy JM, Claas F. Impact of HLA diversity on donor selection in organ and stem cell transplantation. Hum Hered. 2013;76: 178-86.

30. Tram K, Stritesky G, Wadsworth K, Ng J, Anasetti C, Dehn J, et al. Identification of DPB1 permissive unrelated donors is highly likely. Biol Blood Marrow Transplant. 2017;23:81-6.

31. Petersdorf EW, Gooley T, Malkki M, Anasetti C, Martin P, Woolfrey $A$, et al. The biological significance of HLA-DP gene variation in haematopoietic cell transplantation. $\mathrm{Br}$ J Haematol. 2001;112:988-94.

32. Mack S, Meyer D, Single R, Sanchez-Mazas A, Thomson G, Erlich HA. 13th International Histocompatibility Workshop Anthropology/Human Genetic Diversity Joint Report. Ch. 1. Introduction and Overview. HLA, 2004. Immunobiology of the Human MHC. Seattle: international Histocompatibility Workshop and Conference; 2004. p. 1-4.

33. Rossman MD, Thompson B, Frederick M, Maliarik M, lannuzz MC, Rybicki BA, et al. HLA-DRB1*1101: a significant risk factor for sarcoidosis in blacks and whites. Am J Hum Genet. 2003 73:720-35

34. Weiskopf D, Grifoni A, Arlehamn CSL, Angelo M, Leary S, Sidney J, et al. Sequence-based HLA-A, B, C, DP, DQ, and DR typing of 339 adults from Managua, Nicaragua. Hum Immunol. 2018; 79:1-2.

35. Noble JA, Valdes AM. Genetics of the HLA region in the prediction of Type 1 diabetes. Curr Diab Rep. 2011;11:533-42.

36. Hollenbach JA, Madbouly A, Gragert L, Vierra-Green C, Flesch S, Spellman S, et al. A combined DPA1 DPB1 amino acid epitope is the primary unit of selection on the HLA-DP heterodimer. Immunogenetics. 2012;64:559-69.

37. Lázaro AM, Moraes ME, Marcos CY, Moraes JR, Fernández-Viña MA, Stastny $P$, et al. Evolution of HLA-class I compared to HLAclass II polymorphism in terena, a South-American Indian tribe. Hum Immunol. 1999;60:1138-49

38. Trachtenberg EA, Keyeux G, Bernal JE, Rhodas MC, Erlich HA. Results of expedicion humana. I. Analysis of HLA class II (DRB1- 
DQA1-DPB1) alleles and DR-DQ haplotypes in nine Amerindian populations from Colombia. Tissue Antigens 1996;48:174-81.

39. Cerna M, Falco M, Friedman H, Raimondi E, Maccagno A, Fernandez-Viña $M$, et al. Differences in HLA class II alleles of isolated South American Indian populations from Brazil and Argentina. Hum Immunol. 1993;37:213-20.

40. Layrisse Z, Guedez Y, Domínguez E, Paz N, Montagnani S, Matos $\mathrm{M}$, et al. Extended HLA haplotypes in a Carib Amerindian population: the yucpa of the perija range. Hum Immunol. 2001; 62:992-1000.

41. Gendzekhadze K, Herrera F, Montagnani S, Balbas O, Witter K, Albert $\mathrm{E}$, et al. HLA-DP polymorphism in venezuelan amerindians. Hum Immunol. 2004;65:1483-8.

42. Omrani AS, Almaghrabi RS. Complications of hematopoietic stem cell transplantation: bacterial infections. Hematol Oncol Stem Cell Ther. 2017;10:228-32.

43. Yan $\mathrm{CH}, \mathrm{Xu}$ LP, Wang FR, Chen $\mathrm{H}$, Han W, Wang $Y$, et al. Causes of mortality after haploidentical hematopoietic stem cell transplantation and the comparison with HLA-identical sibling hematopoietic stem cell transplantation. Bone Marrow Transplant. 2016:51:391-7.

44. Weisdorf D, Zhang MJ, Arora M, Horowitz MM, Rizzo JD, Eapen $M$, et al. Graft-versus-host disease induced graft-versus-leukemia effect: greater impact on relapse and disease-free survival after reduced intensity conditioning. Biol Blood Marrow Transplant. 2012;18:1727-33

45. Frangoul $H$, Jagasia M. Relapse post hematopoietic SCT remains the achilles heel for the field. Bone Marrow Transplant. 2014; 49:997-8.

46. D'Souza A, Lee S, Zhu X, Pasquini M. Current use and trends in hematopoietic cell transplantation in the United States. Biol Blood Marrow Transplant. 2017;23:1417-21.

47. Shaw BE, Gooley TA, Malkki M, Madrigal JA, Begovich AB, Horowitz MM, et al. The importance of HLA-DPB1 in unrelated donor hematopoietic cell transplantation. Blood. 2007; 110 4560-6

48. Petersdorf E, Bardy P, Goulmy E, Hansen J, Schwarer A. Clinica importance of HLA-DPB1 in haematopoietic cell transplantation. Tissue Antigens. 2007;1:17-24

49. Gu B, Zhang X, Chen G, Wu X, Ma X, Chen S, et al. Efficacy of haploidentical hematopoietic stem cell transplantation compared to HLA-matched transplantation for primary refractory acute myeloid leukemia. Ann Hematol. 2018 97:2185-94

50. Fleischhauer $\mathrm{K}$, Beelen DW. HLA mismatching as a strategy to reduce relapse after alternative donor transplantation. Semin Hematol. 2016;53:57-64

51. Burroughs LM, O’Donnell PV, Sandmaier BM, Storer BE, Luznik L, Symons HJ, et al. Comparison of outcomes of HLA-matched related, unrelated, or HLA-haploidentical related hematopoietic cell transplantation following nonmyeloablative conditioning for relapsed or refractory hodgkin lymphoma. Biol Blood Marrow Transplant. 2008;14:1279-87.

52. Yang B, Yu R, Cai L, Bin Guo, Chen H, Zhang H, et al. Haploidentical versus matched donor stem cell transplantation for patients with hematological malignancies: a systemic review and meta-analysis. Bone Marrow Transplant. 2019;54:99-122.

53. Berger M, Lanino E, Cesaro S, Zecca M, Vassallo E, Faraci M, et al. Feasibility and outcome of haploidentical hematopoietic stem cell transplantation with post-transplant high-dose cyclophosphamide for children and adolescents with hematologic malignancies: an AIEOP-GITMO retrospective multicenter study. Biol Blood Marrow Transplant. 2016;22:902-9.

54. Uygun V, Karasu G, Daloğlu H, Öztürkmen S, Çakı Kılıç S, Hazar $\checkmark$, et al. Haploidentical hematopoietic stem cell transplantation with post-transplant high-dose cyclophosphamide in high-risk children: a single-center study. Pediatr Transplant. 2019; 23:e13546 